\title{
The Australian Sugar Industry Museum
}

\section{Jan Lahney}

\section{Steam, fire and hard yakka created the successful sugar cane industry!}

There is more to the sweet tropical grass than the addictive sweet taste, however, and there is more to the Australian Sugar Museum, on the corner of the Bruce Highway and Peregrine Street, Mourilyan, south of Innisfail in far north Queensland, than a collection of old farming equipment.

Within its celebration of the sugar industry and the workers whose sweat watered the cane fields, there is an ongoing celebration of learning and art that is affecting not only Queensland but Australia as a whole.

The museum concept at Mourilyan is taken out of the cliché, dusted off, and brought alive! Innovative historical displays, equipment, photography, artefacts and past cultures live again in one wing; and counterpoint with today's photography, poetry, music, food, fabrics, and learning in a creative explosion of new century life, which is displayed in the modern Sugarama Gallery of the second wing. 


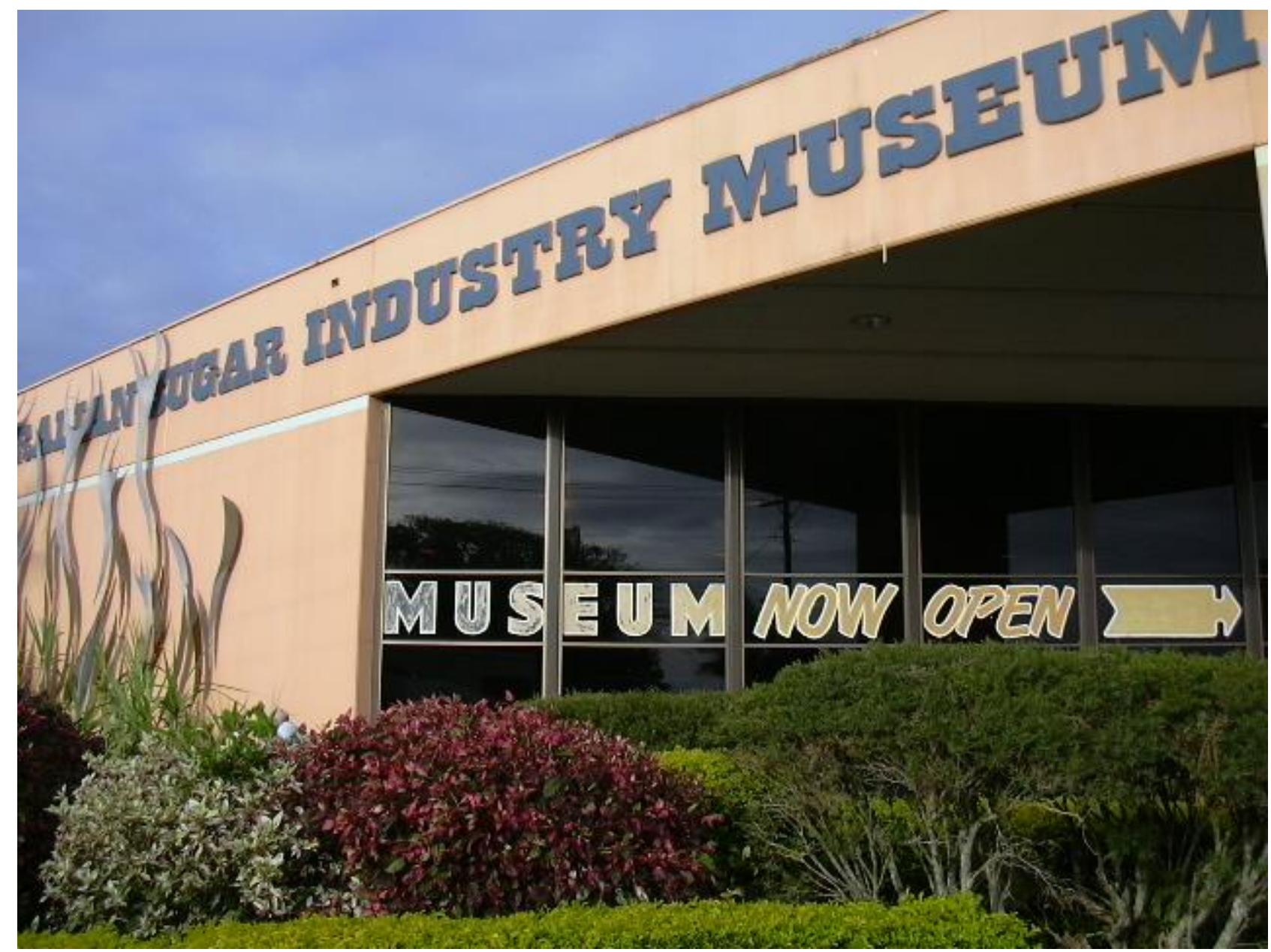

The National Museum in Canberra this year will house a well-defined collection from the Australian Sugar Museum, Refined White, which focuses on the Queensland sugar industry and the influence of 62,000 South Sea Islanders from the 1860s to Federation.

Refined White is a historical collection of photographs and artefacts that defines the history of the South Sea Islander peoples - their physical work and influence on an Australian society which instead of gratitude showed a distain that spawned the White Australia Policy.

A well-travelled collection, Refined White has toured the eastern seaboard from Mourilyan to Melbourne since 2001, and has included showings on the Sugar Trail from Mossman in north Queensland to Maclean in New South Wales. The full exhibition route included Townsville, Mackay, Rockhampton, Bundaberg, Gladstone, Stanthorpe, Brisbane, Caloundra, Maclean and south to Sydney and Melbourne. Conceived in 1998, the collection was to add an essential piece to the ever-expanding historical jigsaw being established at the Mourilyan museum. 
Research highlighted the need to extend the parameters of the collection past merely recording the contribution made by the Islander people to include an awareness of the richness of their culture that was sadly lacking in mainstream Australia.

Curator of the Australian Sugar Museum, John Waldron, says the change of direction of the collection was a rewarding decision that evolved into the inclusion of a major educational resource to complement the collection.

Designed to meet the Studies of Society and Environment syllabus for secondary school students from years $8-12$, the educational package compiled by researcher and writer, Michael Berry, targets "social, legal and political issues as well as history and citizenship" pedagogy.

A multi-layered concept, the reader-friendly information goes beyond the revealing photographs of a strong, saddened people, to inviting the literary explorer to read, research, role play, reflect and re-evalute the history and attitudes that moulded Queensland.

Attitudes are probed. Knowledge is probed. Focus questions prompt the reader to confront the past and the ramifications for the black society then and the multi-cultural society now: Could Queensland have separated from Australia over the issue of black labour? What does it mean to be racist? Are there certain rights and freedoms that all of us are entitled to? What does it mean for everyone to be equal?

Boxed snippets of information, (pros and cons of slavery raised at the time of blackbirding or the details of the excluding dictation test that applied to unwelcome immigrants), tease the reader with just enough pertinent information to prompt further questioning and reading.

Teasers pepper the pages. Teasers of information, (what a bill of rights should contain or details of food rations or wages), reminders to compare the information with other known facts: for instance, what should be the inherent freedoms for all and what they really were for the South Sea Islander.

Cartoons, capsules of biting satire and insight, taken from newspapers reveal $19^{\text {th }}$ century attitudes ranging from being purely racist to seeing the black labour as the slavery it really was. 
"There are many humorous things in the world, among them the white man's notion that he is less savage than the other savages" Mark Twain 1897 - and with this quote Michael Berry reminds the reader of the savage paternalism and exploitation of the black man and woman by their whiter brothers and sisters.

Berry quotes the Premier of Queensland, Peter Beattie, speaking to the Queensland Parliament on September 1999, acknowledging that though the back-breaking work of the South Sea Islanders enriched the state of Queensland — then, "we kicked them out".

The Queensland Government statement acknowledges the unjust treatment, the social and economic disadvantage, prejudice and racial discrimination and ongoing disadvantages suffered by these people and has now formally recognised the culture's existence and contribution to Queensland.

Refined White, as an educational package is not just focused on the past. It acknowledges the present contribution made by South Sea Islanders in all walks of life, and details the export of $80 \%$ of the product and the uses of the remaining $20 \%$ for domestic use.

But learning about sugar does not stop with the contribution of the people of the Pacific, it extends to include the migrant people and Australians who farmed the sweet grass since 1788. Berry says an average of 12 tonnes of sugar comes from every hectare that grows 95 tonnes of cane and adding a total average of $\$ 5$ billion to the Australian economy each year.

Four million tonnes of Queensland raw sugar are created by the sugar industry for markets from Asia to Saudi Arabia and to Canada and the USA, and the industry potential attracts political attention worthy of an economically important product. State Member for Hinchinbrook, Mark Rowell, announced in parliament in October 2003 that a group of sugar industry figures were investigating the expansion of ethanol production as a major earning component for the industry. 


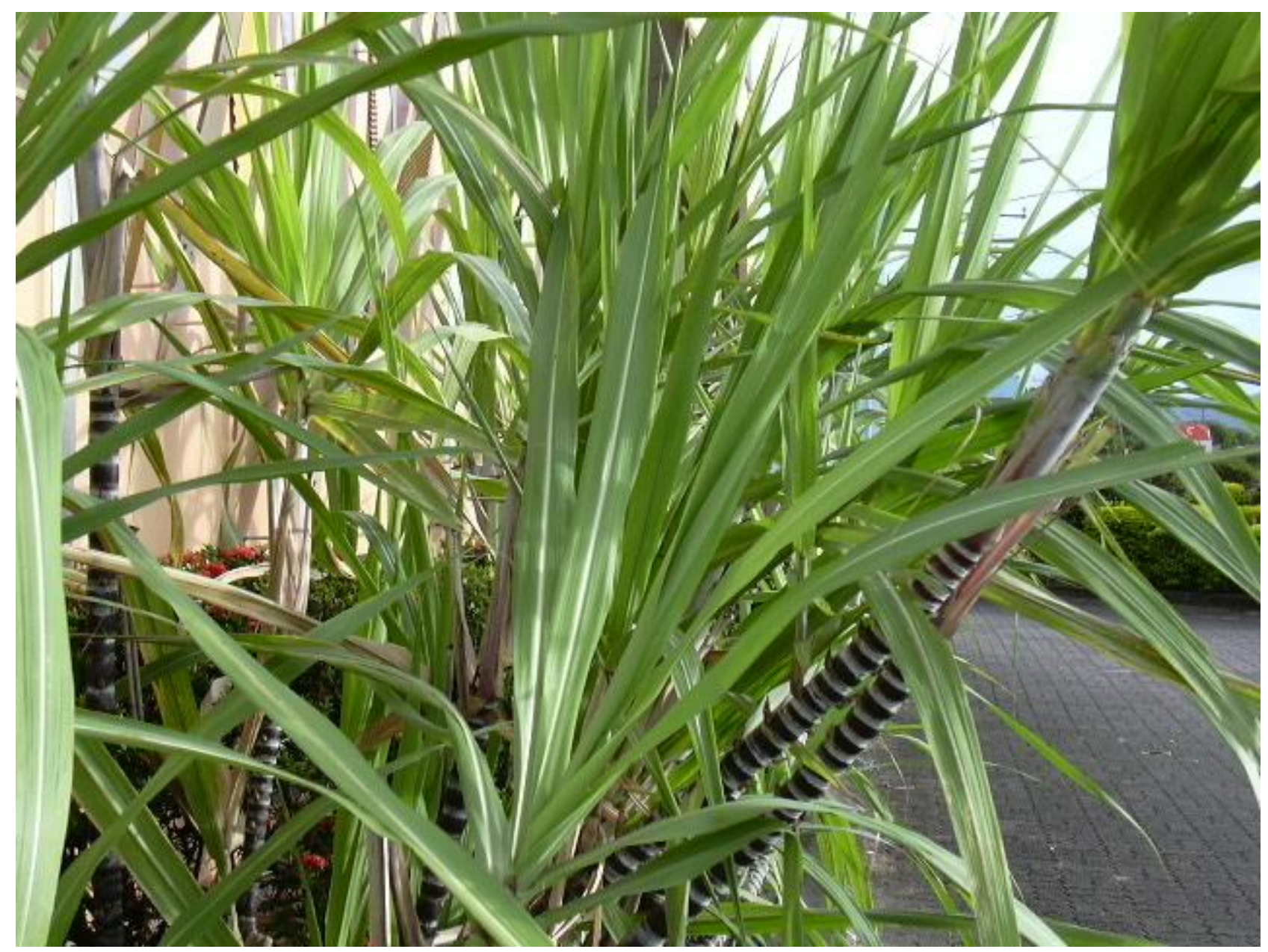

Travellers from outside the local area are especially drawn to the collection of items, domestic and farming, that were part of the lives of the workers who created the successful sugar economy. In the days before sugar was considered a new source of power, the sugar gatherers had to be content with simple but functional appliances and furniture: the bush safe that hung from a beam or a bush and kept the food cool and insect free and was later replaced with the ice chest, the forerunner of the refrigerator; the doubly serviceable kerosene tins that were converted into drawers or other storage areas once their load had been discharged; the multi-adaptable sugar bag that became a welcome mat to wipe off the tropical mud, a carpet, curtains, a mattress or a shopping bag; the tin of treacle or syrup on the table that spoke of its sugary beginnings standing next to the tea caddy that protected the basis of the necessary brew; the kerosene lamp that pre-electricity, threw minimal light around the cane-cutter's barracks; the simple, once-white sandshoes that gave grip in fair weather and foul; and the wood stove; these and many more are frozen in time at the Mourilyan Museum . And of course the ever-ready cane knife has its own tale to tell. 
Cane knives were not all the same. The original cutting tool, a flat, broad bladed knife that included a hook, was adapted by bending it in a fire of some 400 degrees Fahrenheit, and then shaped to favour the particular cutter's skills. Handles were polished with broken bottle glass, and behind the hook that was used to rake away the trash, weights were added to create a simple, but effective, individualised tool.

These knives were wielded with deadly precision by the cane cutters as was discovered by many a snake in the cane fields and in the cottages. (The author's grandfather, John Brogden, in a cane barracks in Giru, neatly decapitated a snake with a swipe from his cane knife, when the snake, having dropped half his length from the rafters, suddenly appeared suspended in front of the man's face. The Englishman was surprised, and somewhat dismayed, when he realised that after the swipe, the snake's head had dropped down the front of his navy "Jackie Howe" singlet ... he later admitted to his family, "I did a little dance").

Both cane knives and Australian raw sugars that grace the tables of the world (see below) have their own mini displays in the hall that connects the two major museum areas.

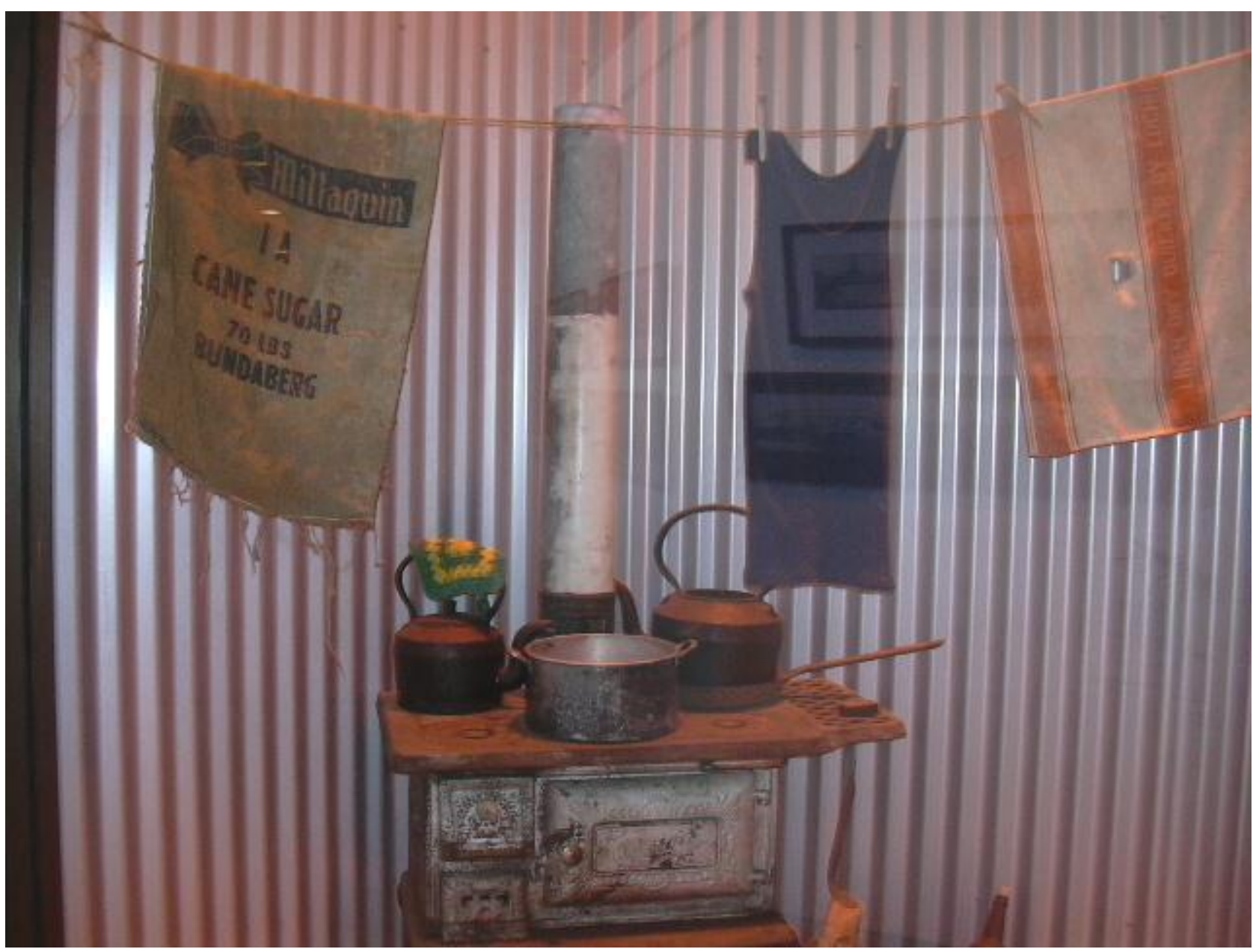


The permanent display space of 14,000 square metres, is dominated by the 500 steam driven crushing engine, which was rescued from the Goondi Sugar Mill after it closed. Believed to bethe largest of its type in the Southern Hemisphere, the enormous machine that towers over people, (see below) was built in Glasgow Scotland in 1950 and performed its last crush in 1986.

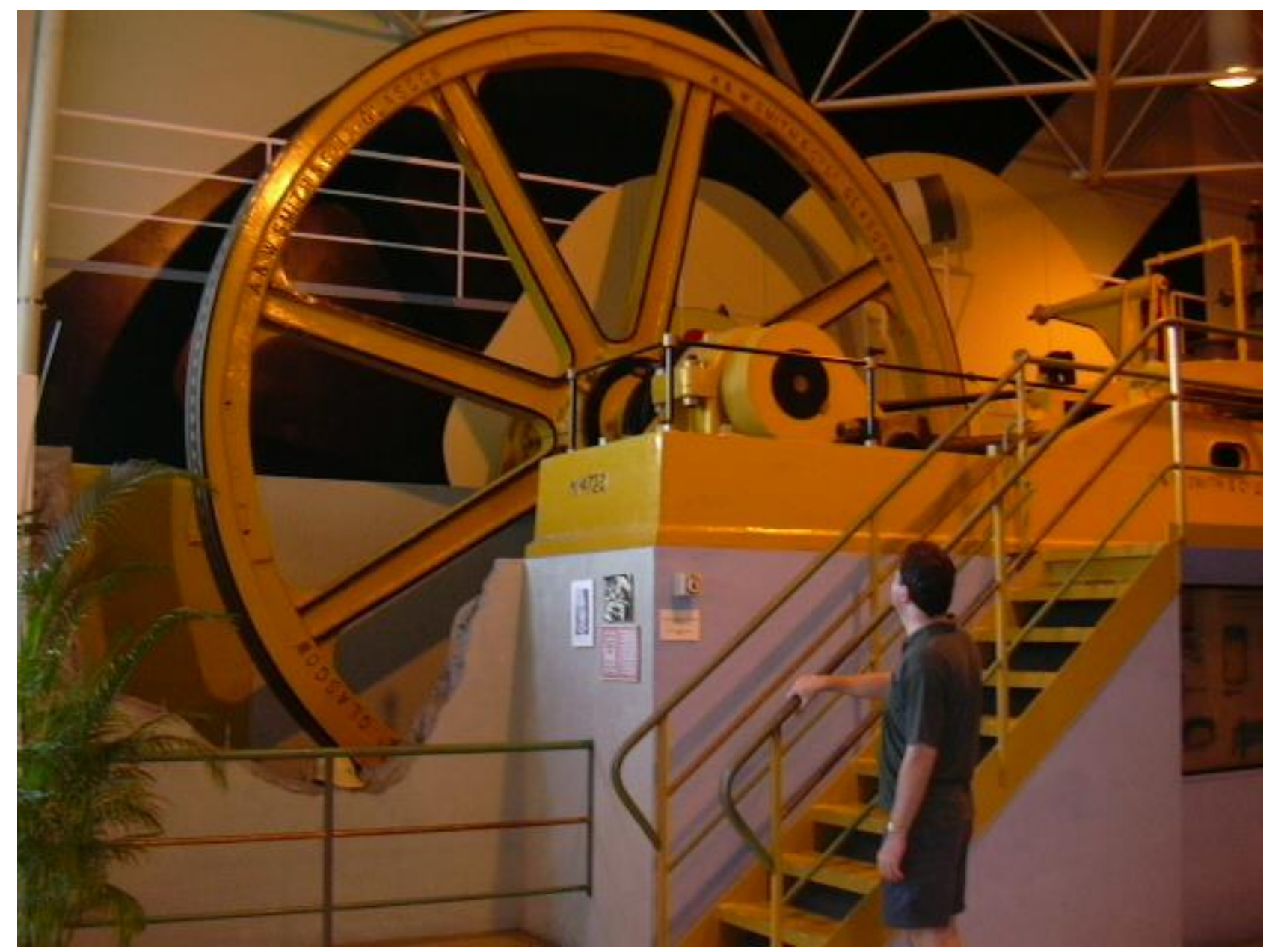

Intrigued machine buffs can, with the flick of a switch, actually re-activate the mammoth crusher engine that shares the space with the first process IBM computer, complete with some of the old input cards, to be used in the sugar industry.

In the collection of harvesters, locomotives and historical tractors, one of the most interesting is Percy Benn's tractor from El Arish. This far-sighted man who was eventually to become the Director of the Tully Sugar Mill and a councillor in the Tully Shire Council, (1949-1967), became involved with the sugar industry after World War 1. As a returned soldier he was entitled to a soldier's settlement of land, which, fortunately for him, was already half cleared and supported some sugar cane. 
Necessity being the mother of invention, he modified his Fordson tractor by building up its steel wheels with timber, (see photo) raising the tractor above the young cane, and preventing damage to the crop. The specialised tractor also boasts a predecessor to the 3 point linkage system. This pioneer cane farmer, who once cleared his property with an axe and a cross cut saw, lives forever in the celebration of cane history.

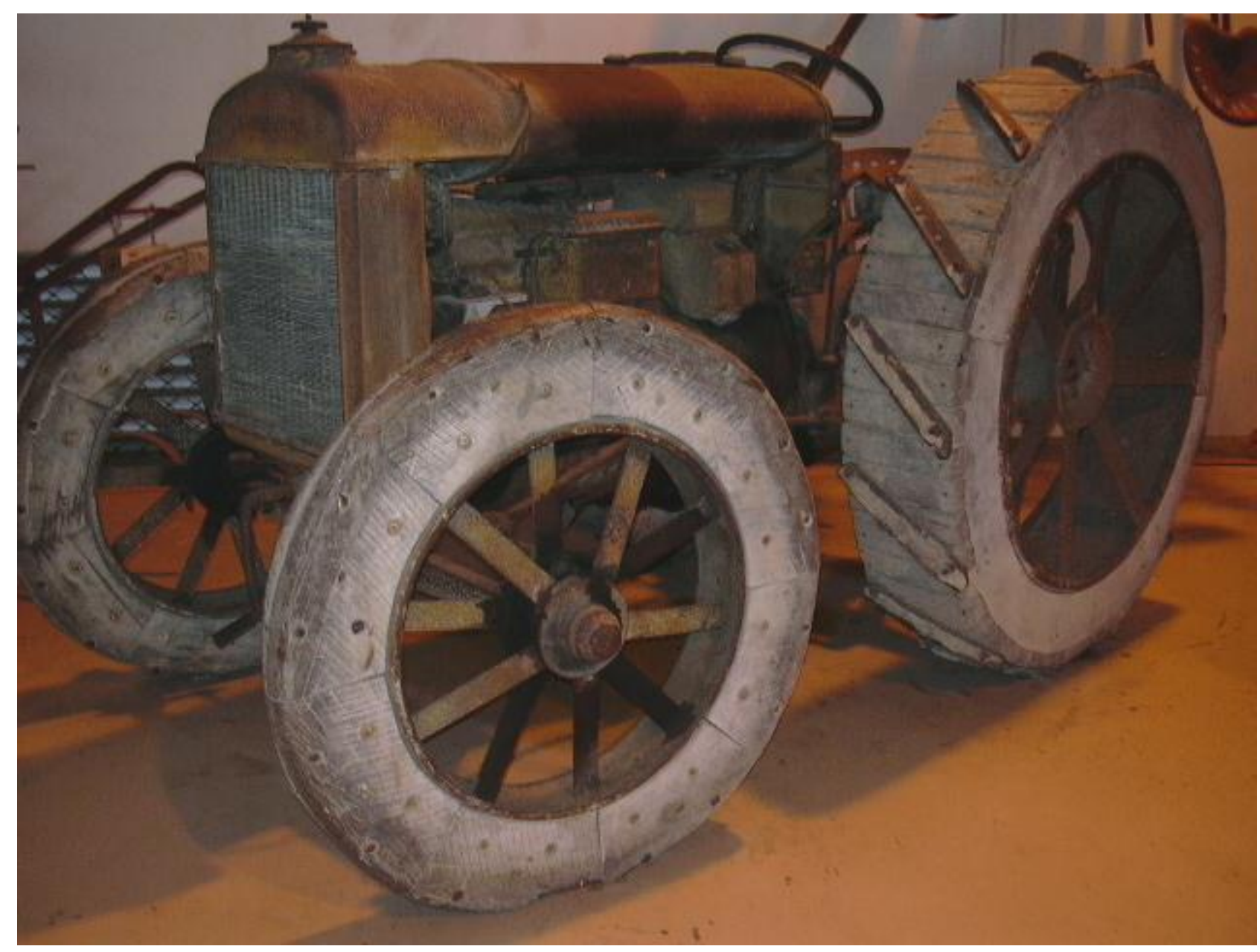

The only major facility in Australia that is dedicated to sugar heritage houses other large equipment including locomotives, harvesters and a flat bed truck (see below) that provided basic transport from farm to town. 


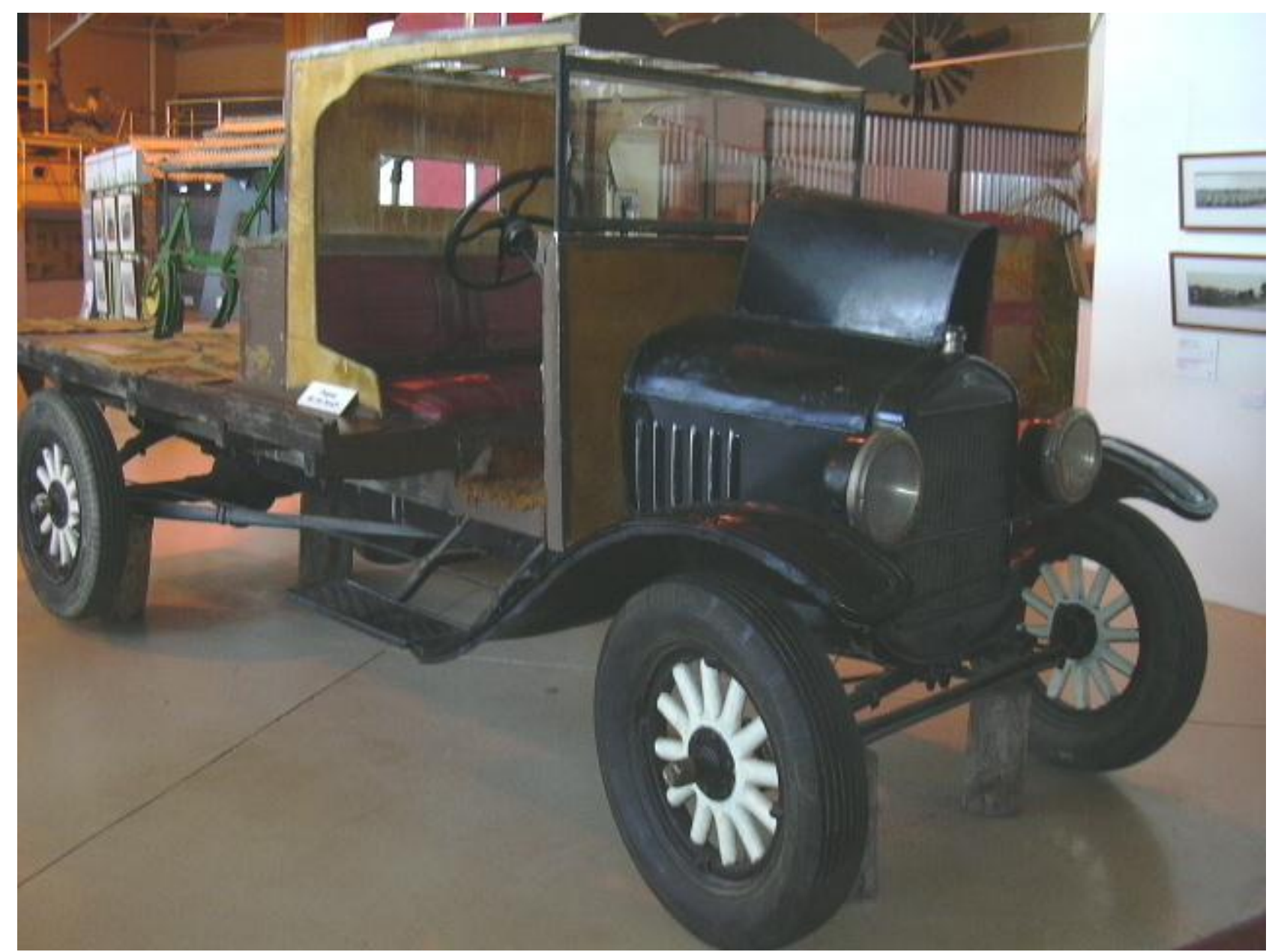

While the vehicles attract attention because of their size or unique qualities, and the collection of smaller domestic objects, like unusual sugar bowls, from china to fine silver are worth a look, it is the collection of photographs that are particularly edifying in re-creating past eras.

Robert Belbin takes the viewer back to the nineteen twenties with his striking black and white panorama photographs. Contact prints with Kodak Verichrome film, the images measure $90.5 \times 15 \mathrm{~cm}$ and within their interesting creative span, reveal slices of life in fascinating detail. Whether encompassing the Inkerman or Tully Mills in an industrial shot, or capturing the fluidity and movement of Mena Creek Falls, or freezing trade action at the corner of Rankine and Edith Streets in Innisfail, or identifying the home owner of an impressive Queenslander, the images caught on glass plate are not only enlightening, but artistically, beautifully balanced.

The eyes of ex-Sydneyite and Australia Sugar Museum curator, John Waldron, light up as he describes the old-time resourceful photographer coming to the sugar area to tote for 
business. He would arrive at a property, like a farm. Look around. Tell the farmer and the family to dress for the photograph to be taken the next day: no obligation to purchase.

When the photographer arrived the next day he would arrange the photograph like an artwork: maybe the farmer in one part of a field, the children with a horse, the mother in another part of the property. Then in one panoramic sweep, he would capture the farm, the house, the people, strategically placed livestock, the fruit trees and in a broad stroke that would sum up their lives. Few people failed to be impressed with their photographs then, and for subsequent generations it is like falling backwards into the pages of a detailed history book.

Alan Hudson, a local historian says he is making "education through history a bit of crusade”. Writing his histories, Sweet Success: a story of South Johnstone Mill (1995) and By the Banyan (2000) published by Christopher Beck, Brisbane, has been a rewarding pastime. Hudson says, this is particularly so, when people in the industry react to some insightful piece of research, with comments like, "God I didn't know that".

A past editor of The Cairns Post, Alan Hudson is out of retirement, and again adding depth to the major local paper in Cairns and the Atherton Tablelands, with historical articles. Sales of the newspaper escalated by $10 \%$ on the days Moments in History were printed. Local history has really captured the locals' interest, and the journalist/historian says the Australian Sugar Museum curator at Mourilyan, John Waldron, is "very capable", and that preservation of local history, is "in good hands".

He agrees with top historian, Henry Reynolds, on the importance of local history books in far North Queensland, and encourages everyone to write their history. Even if only for family consumption initially, as it is part of a wider tapestry, and can prove an invaluable resource for later generations. Pleading for the public to value photographs and information, he recoils at the "Get rid of this stuff" mentality that destroyed so much of the documented past of "the youngest mill that manufactures sugar", in a Tully bonfire. Any extra information he finds, Alan Hudson passes on to the Cairns Historical society; or, as with a panoramic photo of Tully Mill by Lew Stack, returns it to the mill's boardroom where it has pride of place.

The celebration of the cane photographic legacy is ongoing at the museum, beyond the black and whites of Stack and Belbin. The Sugarama Gallery provides for creativity that steps 
beyond the display in the main hall and runs down the connecting hall, past the little post office, the newsagency with its current media publications and books of interest, and to the door of the gallery.

A cane fire photographic exhibition opened at the Sugarama Gallery of the museum in November 2003, in an orchestration of sight, sound and performance poetry. Gallery curator, Waldron, says The Fearful Heart travelling exhibition (showing the special skills of setting and controlling the fires that controlled pests and trash), evolved from the James Cook University honours thesis of Bianka Vidonja, Gentlemen of the Flashing Blade, which was also aired by the $\mathrm{ABC}$.

Photographs were given a special ambience by sound artist, Michael Whiticker, and Innisfail poet, John O'Sullivan, complemented the other artists with a performance of his poem, The Fire in the Paddock, which looked at the destructive force from the point of view of wildlife. The exciting display space in the gallery is perfect for such joint creative effort, (with a projected mezzanine floor for extra storage), the flexible space can house conventions or double as a performing space for arts and drama.

In 2002, the Co-Opera company staged a much-appreciated production of the popular opera, Tosca. An Arts Access Workshop has used the space to explore the needs and opportunities of artists challenged by disabilities, and in 2003 Visual Arts Flying Workshops were held.

Art-forms decorate the outside façade of the main building as well as blossoming in the Sugarama Gallery. Celebrated artist in 2003, Roland Nancarrow, the creator that Ian Smith sees as "a serious Modernist", marries plant and female form in unique fusions of wood and acrylic in elongated static forms, where the themes unfold from the works, sometimes highlighted with two pack automotive paints on marine plastic or aluminium.

Writer, Karen Van Harskamp, notes in Nancarrow's From a Garden Somewhere: sculptural works by Roland Nancarrow 2003 catalogue, that the artist "forays into avian grace, into the fluid lines given to flight, create new relationships within and between his pieces". Acknowledged by the local press as a prolific and regularly commissioned Queensland artist, Nancarrow has collections in major regional centres and Brisbane and Sydney and From a Garden Somewhere is now on tour. He is typical of the quality artists curator Waldron says he wants to attract to the Australian Sugar Industry Museum. 
The drama, heritage and innovations of the sugar industry are an integral part of the history of Queensland, and the Australian Sugar Industry museum caters well for the education of the public. From the videos in the 50 seat theatre to the availability of the educational resource, Michael Berry's Refined White, to the availability of books of history, such as Alan Hudson's Sweet Success: a story of South Johnstone Mill and By the Banyan, for those wanting to explore and know more about north Queensland culture the museum on the Bruce Highway at Mourilyan, just outside Innisfail, is well worth a visit.

Visitors from around Australia, (from among the 15,000 yearly count), who were interviewed were surprised at the depth and interest of material, historical as well as creative, which was on display. Curator, John Waldron, has close liaisons with the community, as a visit to the website address will confirm.

The historical hub of the region is to assist in the development of the 2004 Johnstone Shire Festival and Events Program in this the fiftieth celebratory year of the Harvest Festival and Kulture Karnivale is planned to "celebrate the region's cultural diversity".

The Feast of the Senses, an exotic produce and arts festival in April and May, will give patrons a chance to enjoy exotic fruits, flowers, vegetables, and wine in a culinary explosion spiced up with tips on cooking from a celebratory chef at the gallery.

A double exhibition opened the Sugarama Gallery doors on January 23, 2004 on an exciting black and white surrealistic photography display, Whistling With the Angels, by the Gallery's featured artist for the year, Glen O'Malley. The artist sets up scenarios for shots and then "shoots blind", in underwater environments: stimulating, thought provoking images prompt the viewers to challenge their concept of reality, and draw conclusions - the results "mess with your mind" said one viewer.

Nomadic, the supporting exhibition, is a distinctly innovative display of fibre-arts springing from the "emerging ecofibre, hemp", from the Flying Art Inc. Travelling Exhibition.

This tourism focal point which relies on volunteers, Government grants and patronage to run its centre, which ploughs profits back into development and expansion, won the TTNQ Cultural Awards three years running, from 2001 to 2003. 
Curator, John Waldron is fired with passion to contribute at the AISM to north Queensland where he has made his home, after leaving Sydney culture to the southern rat race, and to share the history he enjoys preserving old ways and celebrating the new at the Australian Sugar Industry Museum on the Bruce Highway.

Enjoy the sweet taste of the tropical sugar at Mourilyan.

\section{Notes}

The Australian Sugar Musem is online at www.sugarmuseum.org.au, and can be contacted by telephone on

0740632656. 